\title{
Saw palmetto, Serenoa repens, in the treatment of benign prostatic hyperplasia, mechanisms of action and reasons for its use
}

\begin{abstract}
Saw palmetto, Serenoa repens, produces berries that are the source of a popular medicine used in the treatment of benign prostatic hyperplasia, prostate infections, prostatitis, chronic pelvic pain syndrome, prostate cancer, hypotonic neurogenic bladder, sexual dysfunction and other conditions. Several clinical trials have been conducted with various extracts of the plant. The results have been mixed. Metaanalyses and systematic reviews of the trials have concluded that S. Repens appears to be effective in the treatment of benign prostatic hyperplasia. The mechanism of action of the medicine is not clear. This review discusses the possibility that medium length fatty acids from $S$. Repens decrease the inflammation of the prostate by altering adipokine secretion from visceral fat. This leads to less hyperplasia and perhaps less risk of promoting prostate cancer.
\end{abstract}

Volume 2 Issue I - 2015

James D Adams, Eric J Lien, Xiaogang Wang
Department of Pharmacology and Pharmaceutical Sciences,

University of Southern, USA

\author{
Correspondence: James D Adams, Department of \\ Pharmacology and Pharmaceutical Sciences, School of Pharmacy, \\ University of Southern California, 1985 Zonal Avenue, Los \\ Angeles, CA, USA, 90089, Tel 3234421362. \\ Email jadams@usc.edu
}

Received: October 3I, 2014 | Published: December 30, 2014

Keywords: saw palmetto, Serenoa repens, benign prostatic hyperplasia, prostate cancer

Abbreviations: Akt, protein kinase $\mathrm{B}$; $\mathrm{BPH}$, benign prostatic hyperplasia; EFK 1/2, elongation factor kinase; HBEGF, heparin binding epidermal growth factor like growth factor; HDL, high density lipoprotein; IL-6, interleukin-6; Inos, inducible nitric oxide synthase; LDL, low density lipoprotein; PDGF, platelet derived growth factor: $\mathrm{TNF} \alpha$, tumor necrosis factor $\alpha$; VEGF, vascular endothelial growth factor

\section{Introduction}

Saw palmetto, Serenoa repens (Arecaceae), is a traditional medicine of American Indians of the southeast. The berries are used as medicine and as food. The leaves are used to make thatching, baskets, fans, brushes, brooms, rope, fire kindling, fish traps and dolls. ${ }^{1}$ European immigrants to the Florida area learned from American Indians to use the berries as medicine. S. Repens is the third most popular plant medicine in the USA and is very popular in Europe. In 2006, it was reported that over 2 million men in the USA used $S$. Repens daily. ${ }^{2}$ Global sales are more than $\$ 700$ million per year, as reported in 2014 by the Valens Company, a manufacturer of the plant medicine. Men are most likely to use $S$. Repens to help with nocturnal urination that prevents them from sleeping through the night. Men use this plant medicine because it helps them with their symptoms.

\section{Discussion}

\section{What is benign prostatic hyperplasia}

Benign prostatic hyperplasia (BPH) is a condition that increases with aging in men over the age of about $40 .{ }^{3}$ By age 60 , about $50 \%$ of men have BPH. The incidence increases to $90 \%$ by age 85 . It involves swelling of the prostate that restricts urine flow. As a result urination becomes difficult, incomplete and sometimes painful. Chronic inability to empty the bladder leads to bladder distention and instability. Enlargement of the prostate involves hyperplasia of stromal and glandular cells. This hyperplasia appears to be the consequence of inflammation.
Diagnosis depends on the answers to seven questions from the American Urological Association Symptom Index. ${ }^{3}$ These questions concern: how often in the past month has the patient felt that urination was incomplete, how often in the past month the patient had to urinate within 2hours of the previous urination, how often in the past month the patient's urine flow stopped and restarted multiple times during one urination, how often in the past month the patient found it difficult to postpone urination, how often in the past month urine flow was weak, how often in the past month the patient had to strain to begin urination, how many times in the last month did the patient typically get up at night to urinate. A score of 7 or more with a urinary flow rate of $15 \mathrm{~mL}$ per second or less is diagnostic of BPH. Palpation of the prostate through the rectum usually demonstrates an enlarged prostate.

\section{What causes benign prostatic hyperplasia}

The answer to this question is that no one knows. There are many theories. Alpha blockers are considered the drugs of choice for $\mathrm{BPH}$, doxazosin, terazosin, alfuzosin, tamsulosin and silodosin. ${ }^{4}$ This suggests that sympathetic dysfunction is involved in BPH. Finasteride and dutasteride have been shown in clinical trials to improve the symptoms of BPH. ${ }^{5}$ These drugs inhibit 5-alpha-reductase also called 3 -oxo-5 $\alpha$-steroid 4-dehydrogenase, which converts testosterone into dihydrotestosterone. This suggests that dihydrotestosterone may cause or contribute to prostatic enlargement. The antimuscarinic agent, tolterodine, can be used in combination with a $\alpha$ blocker to improve BPH symptoms. ${ }^{6}$ Therefore, autonomic dysfunction may be involved in BPH. Tadalafil improves the symptoms of BPH in patients that suffer from erectile dysfunction and BPH, as approved by the FDA in October, 2011. Tadalafil is a phosphodiesterase type 5 inhibitor, which increases cGMP levels. Smooth muscle cells relax when cGMP levels increase. This suggests that unstable smooth muscles in the prostate or bladder are important in BPH.

Lifestyle is important in BPH.7 Obesity, diabetes; meat and fat consumption are risk factors for BPH. Factors that decrease BPH risk include exercise, moderation in alcohol consumption and eating 
vegetables. Fat, meat and alcohol consumption increase obesity. ${ }^{8}$ As men age, obesity shifts from sub dermal fat to visceral fat accumulation. As visceral fat accumulates, the fat cells and embedded inflammatory cells begin to secrete inflammatory adipokines and toxic lipids. Inflammatory adipokines include interleukin-6 (IL-6), tumor necrosis factor $\alpha(\mathrm{TNF} \alpha)$, heparin binding epidermal growth factor like growth factor (HBEGF), vascular endothelial growth factor (VEGF), platelet derived growth factor (PDGF), visfatin, resistin, resistin like molecules, angiotensin, many adhesion molecules and more. Toxic lipids include ceramide and the endocannabinoids. It should be mentioned that the prostate gland is surrounded by visceral fat. Visceral fat around the prostate gland increases with obesity and retropubic fat pad invasion.

The roles of inflammatory adipokines in prostate dysfunction have been reviewed. ${ }^{9,10}$ Leptin, IL-6, HBEGF and VEGF are inflammatory adipokines that have been shown to increase the growth of prostate tissue. These adipokines may cause $\mathrm{BPH}$ and promote prostate cancer. The roles of endocannabinoids are to increase the release of inflammatory adipokines by visceral fat. ${ }^{8}$ Endocannabinoids also stimulate appetite. The role of ceramide is to cause dysfunction of inducible nitric oxide synthase (iNOS) which decreases NO production and decreases the ability of smooth muscle cells to relax.

Visceral fat possesses aromatase activity that converts testosterone to estrogen. ${ }^{9,10}$ Visceral obesity causes testosterone levels to decrease and estrogen levels to increase. In addition, visceral obesity causes the production of sex hormone binding globulin to decrease. This increases the unbound or active levels of estrogen. Overall, visceral obesity causes the levels of pharmacologically active estrogen to increase. While testosterone levels decrease with aging and visceral obesity, dihydrotestosterone levels remain constant. ${ }^{11}$ This implies that visceral obesity increases the synthesis of dihydrotestosterone from testosterone. Dihydrotestosterone induces the expression of various growth factors that stimulate the growth of the prostate, epidermal growth factor, keratinocyte growth factor, insulin like growth factors and transforming growth factor- $\beta$. Dihydrotestosterone and estrogen work together to increase cell proliferation and decrease cell death in the prostate. This leads to increased prostate mass.

Visceral obesity causes autonomic dysfunction associated with overstimulation of sympathetic outflow from the brain. ${ }^{12}$ This involves several adipokines that interact with the hypothalamus in areas not protected by the blood brain barrier. These interactions stimulate sympathetic outflow from the brain. This sympathetic outflow increases the size of the prostate and the tone of the smooth muscles. ${ }^{13}$ The use of alpha blockers to decrease the tone of prostatic smooth muscle cells is beneficial in patients suffering from BPH. The use of antimuscarinic agents to balance the autonomic outflow from the prostatic plexus is beneficial in these patients also. Visceral obesity causes instability of smooth muscle cells by several mechanisms. ${ }^{8}$ One of these mechanisms involves autonomic imbalance as discussed above. Several adipokines increase smooth muscle cell proliferation, such as angiotensin, PDGF and HBEGF which leads to instability.

The prostate becomes inflamed and painful due to the invasion of inflammatory cells, neutrophils, macrophages, T cells and others. ${ }^{8}$ These cells invade across arterial walls and become embedded in the extracellular spaces of the prostate. TNF $\alpha$ and IL-6 cause inflammation by inducing the secretion of adhesion molecules that cause macrophages and neutrophils to invade the prostate. Macrophages and neutrophils are activated by the adipokines, visfatin and Leptin. They begin to produce oxygen radicals that are damaging to tissues. Inflammation has been recognized as a factor in BPH. A recent meta-analysis concluded that non-steroidal anti-inflammatory agents improve urine flow and decrease the symptoms of $\mathrm{BPH} .{ }^{14}$

\section{What is S. Repens}

$S$. Repens is a plant that is perennial, native to the southeast of the US. It is a shrub with fan like leaves called fronds. They grow to $1 \mathrm{~m}$ in width. The plant grows to a height of $3 \mathrm{~m}$ and produces a panicle of dense whitish flowers. Each flower is about $5 \mathrm{~mm}$ across. A small reddish black drupe 1.5 by $2 \mathrm{~cm}$ is produced. This fruit is the source of the plant medicine. The fruit contains 17 fatty acids, 3 phytosterols and many other compounds. Oleic acid, lauric acid, myristic acid, palmitic acid, linoleic acid, steric acid, linolenic acid, caprylic acid and capric acid are the major fatty acids, in descending order of abundance. The phytosterols are $\beta$-sitosterol, campesterol and stigmasterol, in descending order of abundance. Other components of the fruit include $\beta$-carotene, $\gamma$ - and $\delta$-tocopherol. ${ }^{15}$

\section{What is the pharmacology of S. Repens}

Fatty acids are the most abundant components of the plant medicine. Many people eat too much meat and not enough vegetables. Their diets are deficient in plant derived fatty acids. Free fatty acids are taken up in the gut, packaged into chylomicrons and transported to the liver. In the liver, they are used to make triglycerides, are packaged into lipoproteins that are released into the blood or are released into the blood as free fatty acids. Lipoproteins are taken up by most tissues with the release of the free fatty acids they contain into the cell cytoplasma. Free fatty acids can also be taken up across cell membranes by fatty acid transporter proteins. Cytoplasmic free fatty acids are pharmacologically active. They interact with peroxisome proliferator activated receptors, make eicosanoids and have several other activities.

Lauric acid, myristic acid, oleic acid, linoleic acid and S. Repens extracts inhibit 5-alpha-reductase. ${ }^{16,17}$ These fatty acids also bind to alpha ${ }_{1}$-adrenergic receptors. ${ }^{16} \mathrm{~S}$. Repens extracts alter membrane organization and fluidity by decreasing phosphatidylinositol-4,5bisphosphate levels and Akt phosphorylation. ${ }^{18}$ Treatment of rats with lauric acid or myristic acid decreases prostate weight in rats suffering from testosterone induced prostatic hyperplasia. ${ }^{19}$ Clinical studies have shown the fats found in S. Repens have beneficial effects. Myristic acid increases the docosahexaenoic acid cholesteryl esters found in blood, which may decrease the growth of prostate cells. ${ }^{20}$ Diets rich in lauric acid increase high density lipoprotein (HDL) and decrease visceral adiposity. ${ }^{21-23} \mathrm{An} S$. Repens extract was found to alter adipocyte differentiation through a mechanism involving peroxisome proliferator activated receptor, Efk1/2 and Akt. ${ }^{24}$

The phytosterols in S. Repens are pharmacologically active. Phytosterols decrease total cholesterol and low density lipoprotein (LDL) levels in blood. ${ }^{25,26}$ An S. Repens extract has been shown to be anti-inflammatory, perhaps due to its phytosterols. ${ }^{27}$ It decreases epidermal growth factor induced proliferation of prostate cells, and decreases the production of monocyte chemotactic protein- 1 and granulocyte-macrophage colony-stimulating factor in prostate cells. The major phytosterol in $S$. Repens, $\beta$-sitosterol, has been shown in many clinical trials to improve the symptoms of $\mathrm{BPH} .{ }^{28,29}$

\section{Why do some clinical trials of S. Repens in BPH fail}

There is general agreement that $S$. Repens is effective in the treatment of $\mathrm{BPH},{ }^{30}$ which has been disputed by a recent systematic 
review. ${ }^{31}$ The most widely used plant medicines appear to be extracts that contain lipids and phytosterols. However, some clinical trials of ethanolic $S$. Repens extracts have failed ${ }^{2}$ and have stimulated public officials to not recommend $S$. Repens in the treatment of BPH. It may be that the crude plant medicine is the most effective drug in $\mathrm{BPH}$, not extracts.

No one knows why some clinical trials of $S$. Repens extracts failed. Perhaps lifestyle factors are important variables that were not adequately controlled. As mentioned before, eating too much meat, drinking too much alcohol, not eating enough vegetables and not exercising are important causes of BPH. Perhaps S. Repens is most effective in patients who adopt lifestyle changes to decrease their $\mathrm{BPH}$. It may be important to prevent BPH or decrease the symptoms of BPH by teaching patients how to live healthy, balanced lives. ${ }^{32}$

Randomized, placebo controlled, clinical trials are problematic. ${ }^{33}$ The major problem with any clinical trial is that the body heals itself. Clinicians and the public put too much trust in pills to solve health problems. When a patient in a clinical trial thinks he has been given the drug, there will be a positive or placebo effect. The body heals itself. When a patient in clinical trials thinks he is on the placebo, there will be a negative or nocebo effect. The patient wills himself to not heal.

\section{What are the drug interactions with S. Repens}

Drug interactions with $S$. Repens do occur, but are uncommon. ${ }^{34,35}$ Most clinical trials of $S$. Repens found no drug interactions. ${ }^{36}$ Clinical studies of $S$. Repens have shown that cytochrome P450 activity does not increase for any cytochrome P450 subtype. ${ }^{37,38}$ However, S. Repens does inhibit human UGT1A1 activity ${ }^{39}$ which may be the basis for some drug interactions. Platelet function is not altered by S. Repens administration. ${ }^{40}$ Bleeding during surgery is not increased by $S$. Repens. ${ }^{41}$ However, coagulopathy and hematuria in one patient due to $S$. Repens have been reported. ${ }^{42}$ Therefore, it might be safe; to avoid combining $S$. Repens with drugs that slow coagulation such as aspirin, clopidogrel, diclofenac, ibuprofen, naproxen, dalteparin, enoxaparin, heparin and warfarin. It might be safe to avoid combining $S$. Repens with herbal medications that slow coagulation such as willow, angelica, clove, danshen, garlic, ginger, gingko and ginseng.

There is a report of $S$. Repens interfering with estradiol binding to its receptor. ${ }^{43}$ This suggests that women on birth control pills and estrogens in general, can be advised to avoid using S. Repens. It is clear that $S$. Repens interacts with alpha blockers to improve therapy for BPH. ${ }^{44}$ However, ethanolic extracts of $S$. Repens contain tyramine that has indirect sympathomimetic effects. ${ }^{45}$ Tyramine can cause contraction of prostatic tissues and discomfort. The presence of tyramine in $S$. Repens preparations in some clinical trials may explain why these trials failed. Lipidicsterolic extracts of $S$. Repens have not been shown to contain tyramine and should be recommended in BPH. Other rare problems with $S$. Repens include rhabdomyolsysis and pancreatitis. ${ }^{46-48}$ It might be safe to avoid use of $S$. Repens in patients with histories of these diseases.

\section{Conclusion}

The most powerful way to treat BPH is prevention. Healthcare professionals should educate their patients in how to live in balance and prevent $\mathrm{BPH}$ and many other diseases. Patients must learn that obesity is a health hazard. In obesity, appearance is not the issue. Health is the issue. Sometimes drugs and medical care are needed even in fairly healthy people. This is when $S$. Repens and other medicines can be used, for as short a term as possible. Every drug has side effects. Every drug is toxic. Patients must learn to not let a drug become necessary for their health maintenance over the long term. Living in balance allows the body to heal itself.

\section{Acknowledgements}

None.

\section{Conflict of interest}

Author declares that there is no conflict of interest.

\section{References}

1. Moerman DE. Native American Ethnobotany. Portland: Timber Press; 1998. p. $527-528$

2. Bent S, Kane C, Shinohara K, et al. Saw Palmetto for Benign Prostatic Hyperplasia. N Engl J Med. 2006;354:557-566.

3. Barry MJ, Fowler FJ, OLeary MP, et al. The American urological association symptom index for benign prostatic hyperplasia. The measurement committee for the American urological association. $J$ Urol. 1992;148(5):1549-1557.

4. Black L, Naslund MJ, Gilbert TD Jr, et al. An examination of treatment patterns and costs of care among patients with benign prostatic hyperplasia. Am J Managed Care. 2006;12(4 Suppl):S99-S110.

5. Gormley GJ, Stoner E, Bruskewitz RC, et al. The effect of finasteride in men with benign prostatic hyperplasia. $N$ Engl $J$ Med. 1992;327(17):1185-1191.

6. Kaplan SA, Roehrborn CG, Rovner ES, et al. Tolterodine and tamsulosin for treatment of men with lower urinary tract symptoms and overactive bladder: arandomized controlled trial. JAMA. 2006;296(19):2319-2328.

7. Parsons JK. Lifestyle factors, benign prostatic hyperplasia, and lower urinary tract symptoms. Curr Opin Urol. 2011;21(1):1-4.

8. Adams J, Parker K. Extracellular and intracellular signaling. Royal Society of Chemistry, London; 2011.

9. Baillargeon J, Rose DP. Obesity, adipokines, and prostate cancer. Int J Oncol. 2006;28(3):737-745

10. Mistry T, Digby JE, Desai KM, et al. Obesity and prostate cancer: a role foradipokines. Eur Urol. 2007;52(1):46-53.

11. Carson C, Rittmaster R. The role of dihydrotestosterone in benign prostatic hyperplasia. Urology. 2003;61(4 Suppl 1):2-7.

12. Smith MM, Minson CT. Obesity and adipokines: effects on sympathetic overactivity. J Physiol. 2012;590(Pt 8):1787-1801

13. McVary KT, Rademaker A, Lloyd GL, et al. Autonomic nervous system overactivity in men with lower urinary tract symptoms secondary to benign prostatic hyperplasia. J Urol. 2005;174 (4 pt 1):1327-1343.

14. Kahokehr A, Vather R, Nixon A, et al. Non-steroidal anti-inflammatory drugs for lower urinary tract symptoms in benign prostatic hyperplasia: systematic review and meta-analysis of randomized controlled trials. BJU Int. 2013;111(2):304-311.

15. Schantz MM, Bedner M, Long SE, et al. Development of saw palmetto (Serenoa repens) fruit and extract standard reference materials. Anal Bioanal Chem. 2008;392(3):427-438.

16. Abe M, Ito Y, Oyunzul L, et al. Pharmacologically relevant receptor binding characteristics and 5alpha-reductase inhibitory activity of free fatty acids contained in saw palmetto extract. Biol Pharm Bull. 2009;32(4):646-650. 
17. Scaglione F, Lucini V, Pannacci M, et al. Comparison of the potency of different brands of Serenoa repens extract on 5alpha-reductase types 1 and 2 in prostatic co-cultured epithelial and fibroblast cells. Pharmacology. 2008;82(4):270-275.

18. Petrangeli E, Lenti L, Buchetti B, et al. Lipido-sterolic extract of Serenoa repens (LSESr, Permixon) treatment affects human prostate cancer cell membrane organization. J Cell Physiol. 2009;219(1):69-76.

19. Veeresh Babu SV, Veeresh B, Patil AA, et al. Lauric acid and myristic acid prevent testosterone induced prostatic hyperplasia in rats. Eur $J$ Pharmacol. 2010;626(2-3):262-265.

20. Dabadie H, Peuchant E, Bernard M, et al. Moderate intake of myristic acid in the sn-2 position has beneficial lipidic effects and enhances DHA of cholesteryl esters in an interventional study. J Nutr Biochem. 2005;16(6):375-382.

21. Liau KM, Lee YY, Chen CK, et al. An open label pilot study to assess the efficacy and safety of virgin coconut oil in reducing visceral adiposity. ISRN Pharmacol. 2011;2011:949686.

22. Assunçao ML, Ferreira HS, dos Santos AF, et al. Effects of dietary coconut oil on the biochemical and anthropometric profiles of women presenting abdominal obesity. Lipids. 2009;44(7):593-601.

23. Mensink RP, Zock PL, Kester AD, et al. Effects of dietary fatty acids and carbohydrates on the ratio of serum total to HDL cholesterol and on serum lipids and apolipoproteins: a meta-analysis of 60 controlled trials. Am J Clin Nutr. 2003;77(5):1146-1155.

24. Villaverde N, Galvis A, Marcano A, et al. Saw palmetto ethanol extract inhibits adipocyte differentiation. J Nat Med. 2013;67(3):619-625.

25. Jones PJ, MacDougall DE, Ntanios F, et al. Dietary phytosterols as cholesterol lowering agents in humans. Can J Physiol Pharmacol. 1997;75(3):217-227.

26. Moghadasian MH, Frohlich JJ. Effects of dietary phytosterols on cholesterol metabolism and atherosclerosis: clinical and experimental evidence. Am J Med. 1999;107(6):588-594.

27. Iglesias-Gato D, Carsten T, Vesterlund M, et al. Androgen independent effects of Serenoa repens extract (Prostsan) on prostatic epithelial cell proliferation and inflammation. Phytother Res. 2012;26(2):259-264.

28. Wilt T, Ishani A, MacDonald R, et al. Beta-sitosterols for benign prostatic hyperplasia. Cochrane Database Syst Rev. 2000;2:CD001043.

29. Kim TH, Lim HJ, Kim MS, et al. Dietary supplements for benign prostatic hyperplasia: an overview of systematic reviews. Maturitas. 2012;73(3):180-185.

30. Natural Standard Authors. Saw palmetto. Natural Standard, USA; 2014.

31. MacDonald R, Tacklind JW, Rutks I, et al. Serenoa repens monotherapy for benign prostatic hypertrophy (BPH): an updated Cochrane systematic review. BJU Int. 2012;109(12):1756-1761.
32. Adams JD.Preventive medicine and the traditional concept of living in balance. World J Pharmacol. 2013;2(3):73-77.

33. Adams JD. Design flaws in randomized, placebo controlled, double blind clinical trials. World J Pharmacol. 2012;1(1):4-9.

34. Flattery M. Herbal therapies and cardiac side effects. Progress in Cardiovascular Nursing. 2008;23(4):187-190.

35. Bressler R. Herb drug interactions: interactions between saw palmetto and prescription medications. Geriatrics. 2005;60(11):32-35.

36. Izzo AA, Ernst E. Interactions between herbal medicines and prescribed drugs an updated systematic review. Drugs. 2009;69(13):1777-1798.

37. Gurley BJ, Gardner SF, Hubbard MA, et al. In vivo assessment of botanical supplementation on human cytochrome $\mathrm{P} 450$ phenotypes: $\mathrm{Ci}$ trus aurantium, Echinacea pupurea, mild thistle and saw palmetto. Clin Pharmacol Ther. 2004;77(5):428-440.

38. Markowitz JS, Donovan JL, Devane CL, et al. Multiple doses of saw palmetto (Serenoa repens) did not alter cytochrome P450 2D6 and 3A4 activity in normal volunteers. Clin Pharmacol Ther. 2003;74(6):536-542.

39. Mohamed MF, Tseng T, Frye RF. Inhibitory effects of commonly used herbal extracts on UGT1A1 enzyme activity. Xenobiotica. 2010;40(10):663-669.

40. Beckert BW, Concannon MJ, Henry SL, et al. The effect of herbal medicines on platelet function: an in vivo experiment and review of the literature. Plast Reconstr Surg. 2007;120(7):2044-2050.

41. Pecoraro S, Annecchiarico A, Gambardella MC, et al. Efficacy of pretreatment with Serenoa repens on bleeding associated with transurethral resection of prostate. Minerva Urol Nefrol. 2004;56(1):73-78.

42. Villanueva S, Gonzalez J. Coagulopathy induced by saw palmetto: a case report. Bol Asoc Med P R. 2009;101(3):48-50.

43. Di Silverio F, D'Eramo G, Lubrano C, et al. Evidence that Serenoa repens extract displays an antiestrogenic activity in prostatic tissue of benign prostatic hypertrophy patients. Eur Urol. 1992;21(4):309-314.

44. Perry R, Milligan G, Anderson P, et al. Real world use of permixon in benign prostatic hyperplasia determining appropriate monotherapy and combination treatment. Adv Ther. 2012;29(6):538-550.

45. Chua T, Simpson JS, Ventura S. Ethanol extracts of saw palmetto contain the indirectly acting sympathomimetic: tyramine. Prostate. 2011;71(1):71-80

46. Hanaka M, Yoshii C, Yatera K, et al. A case of rhabdomyolsysis caused by saw palmetto of healthy foods. J UOEH. 2012;34(2):193-199.

47. Wargo KA, Allman E, Ibrahim F. A possible case of saw palmetto induced pancreatitis. South Med J. 2010;103(7):683-685.

48. Jibrin I, Erinle A, Saidi A, et al. Saw palmetto induced pancreatitis. South Med J. 2006;99(6):611-612. 